\title{
Balanced Scorecard and its Role in Evaluating the Performance of Organizations (Case Study in the Directorate General for the Production of Electric Power/ Middle Euphrates)
}

\author{
Naseem Khudhair Abbas \\ College of Al-Mustaqbal University,Business Administration Department \\ Naseemalshamery@gmail.com
}

Submission date:- 1/3/2018 Acceptance date:- 7/4/2019 Publication date:- 8/4/2019

Keywords: Balanced Scorecard, performance evaluation.

\begin{abstract}
Balanced scorecard is considered a modern form of evaluating the Performance of economic units; as it depend on integrated measure of financial performance presenting a description for performance presenting a description for past events results, besides, depending on un financial measures representing as indicators of future performance.

Accordingly, balanced scorecard allows economic units evaluating their performance with four perspectives, the financial, Customer, internal operation, and education and growth perspective .
\end{abstract}

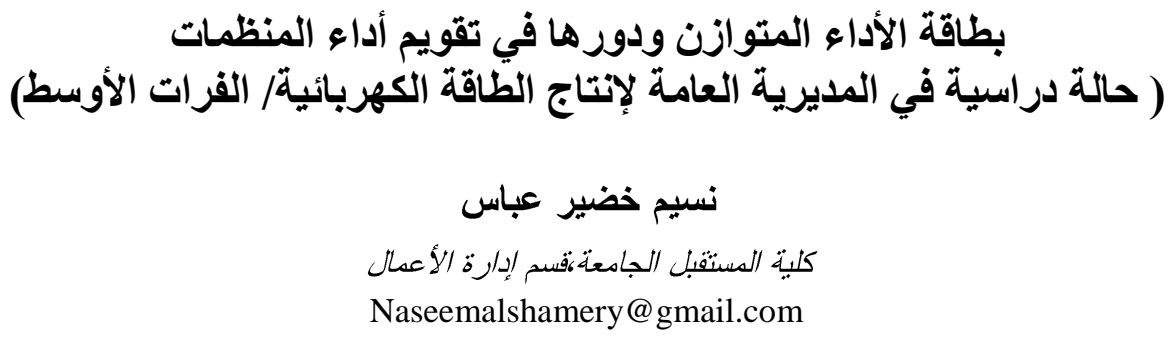


تو اجه بيئة الاعمال المعاصرة العديد من المتغيرات التي من أبرزها المنافسة الثديدة وظهور ثورة تكنولوجية في مجال الانتاج وأنظمة

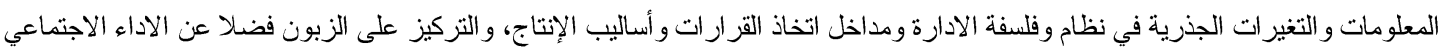
حيث اصبحت تلك المتغير ات تتكل تحديات تو اجه المنظمات . ومع التسليم بوجود هذه المتغيرات في بيئة الاعمال المعاصرة أصبحت عملية تقويم الأداء التقليدية التي تعتمدها الوحدات الاقتصادية في تقويم

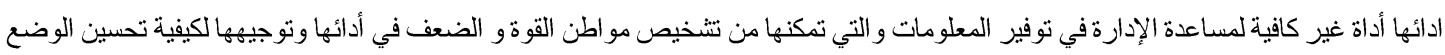
التنافسي لها. قدرتها على الاستمر ار و النمو إذ اعتمدت المحاسبة الادارية التقليديةً على المقاييس المالية فقط في عملية تقويم الاداء وهذه المقاييس أصبحت

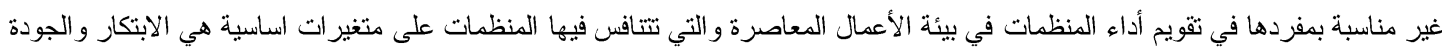

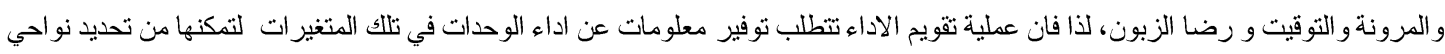
القصور في أنشطتها والعمل على معالجتها وبما تسهم في تعزيز الوضع التتافسي لها.

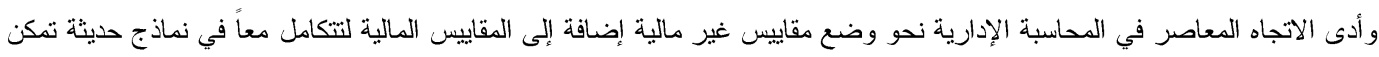

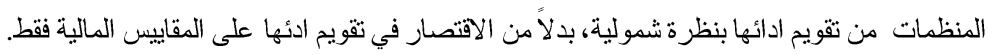

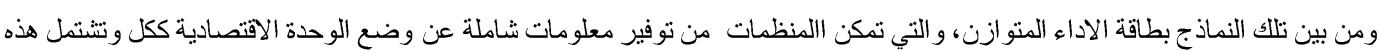
البطاقة من خلال مناظير ها على مقاييس مالية بالإضافة إلى مقاييس غير مالية تركز على رضا الزبون ونئ العمليات الداخلية و التعلم و النمو .

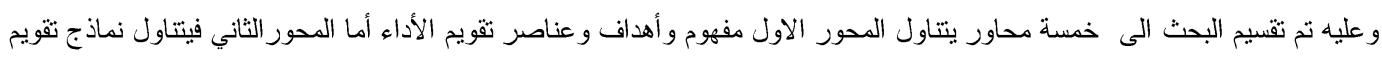

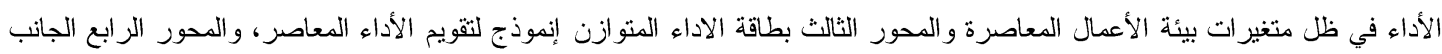

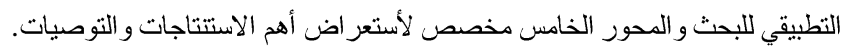

تتطلق مشكلة البحث من أن عملية تقويم الأداء التقليدية المقتصرة على استعمال المقاييس المالية فقط، غير كافية بمفردها لمو اجهة المتغيرات

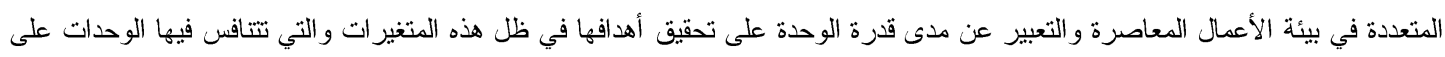

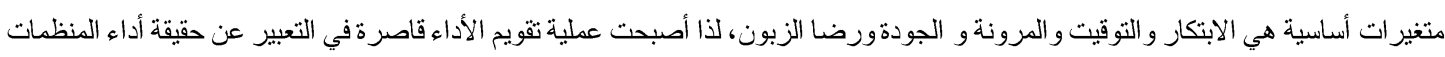

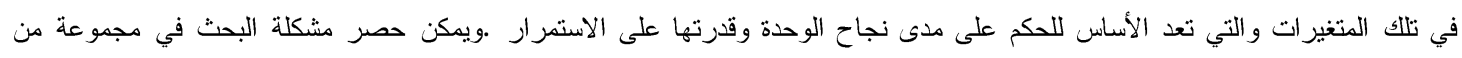
تشاؤ لات:-

1- ما التحديات التي تو اجه المنظمات المعاصرة في عملية تقويم الاداء ؟ تواء r- كيف تساعد بطاقة الاداء المتو ازن في تقويم اداء المنظمات المعاصرة

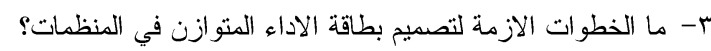

بr تتمثل أهمية البحث في كونه " يحاول تطبيق أحد النماذج الحديثة في تقويم الأداء و المتمثلة ببطاقة الاداء المنو ازن بالثكل الذي يمكن المنظمات

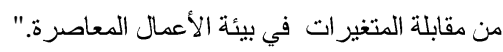

r-r

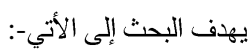

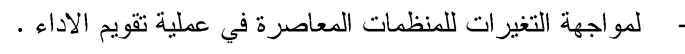

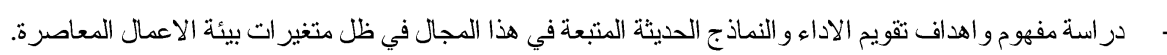

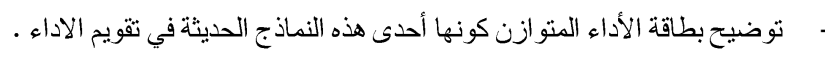

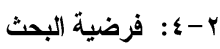

اعتمد الباحث في الإجابة على مشكلة البحث و اهدافه بالفرضية الرئيسة الاتية-:

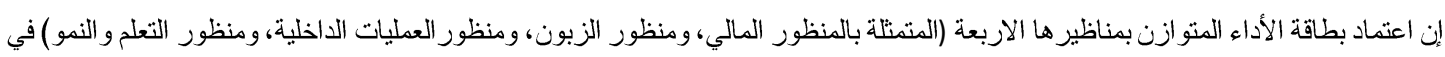

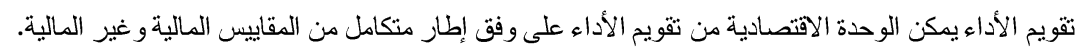




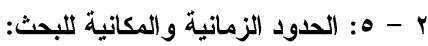

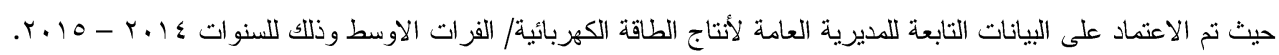

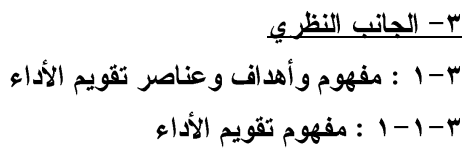

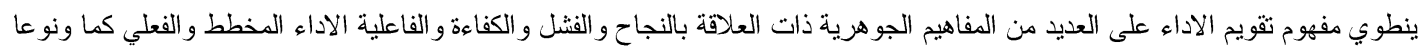
فتثقيم الأداء يميز الأداء الجيد عن الاداء السيء بهدف الاد تطوير الاداء وتحسينه ويعد احد الحلقات المهمة في العملية الادارية الثشاملة لتحقيق أهداف

الوحدة الاقتصادية (1: 10 10).

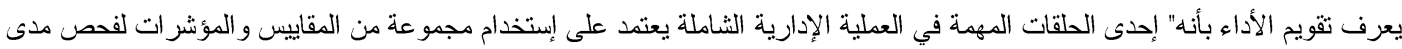

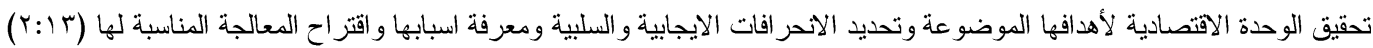

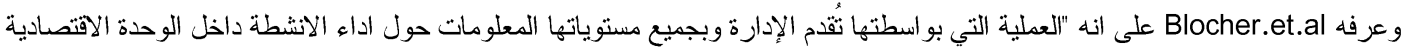

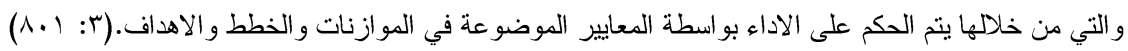

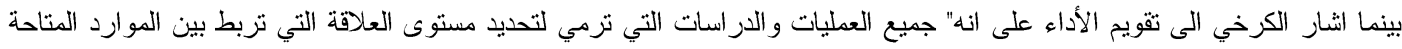

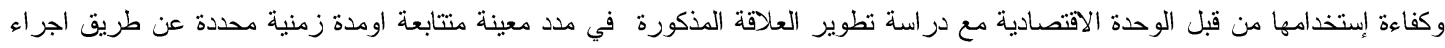

المقارنات بين المستهدف والمتحقق من الاهداف بالاستتاد الى مقاييس ومعاييز معينة (ع: الب).

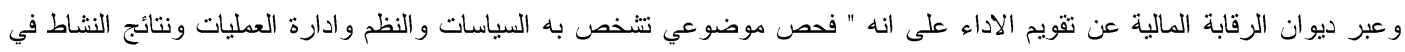

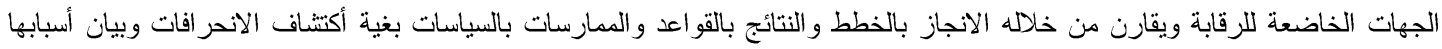

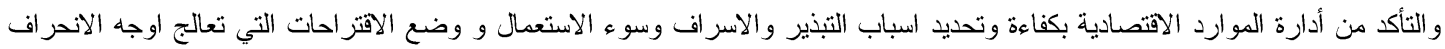

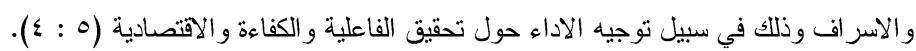

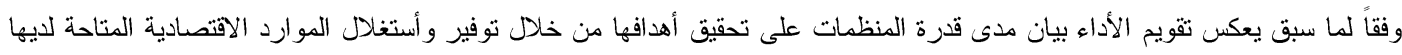

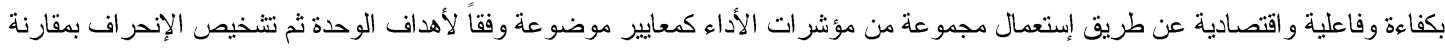

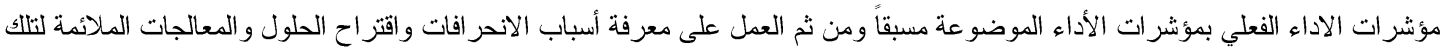

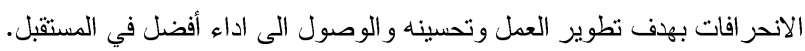

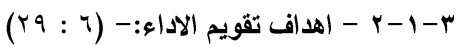
تهدف عملية تقويم الاداء الى تحقيق الاتي:

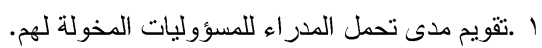
r بتخيص المجالات التي تكون بحاجة الى اجر اءات تصحيحية و العمل على معالجتها.

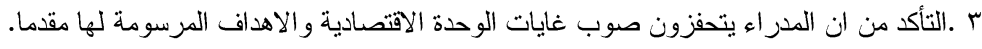

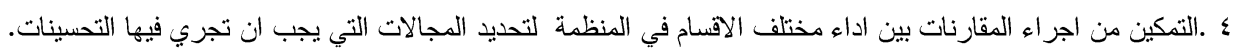

$$
\text { (- }
$$

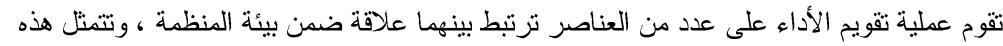

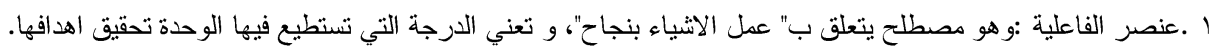

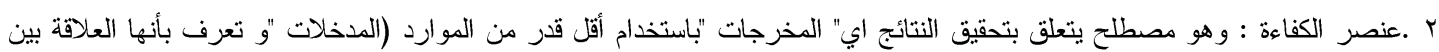
المخرجات من السلع و الخدمات و المو ارد التي أُستخدمت في في انتاجها). r .عنصر الاقتصادية: وهو مصطلح يتعلق بكلف الموارد المستخدمة في انجاز الانشطة المختلفة مع مر اعاة المحافظة على الجودة، كما ان

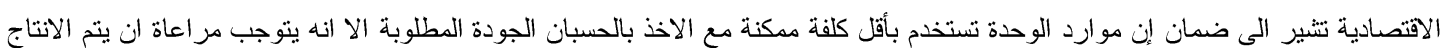

بالكميات المحددة. ؛ .عنصر الاداء الاجتماعي-: و هو مصطلح يتعلق بمسؤولية المنظمة عن تحسين احوال المجتمع والمحافظة على البيئة وتحقيق امان المنتجات

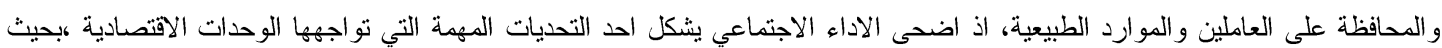

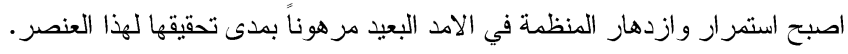


r-r

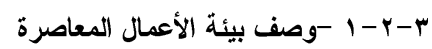

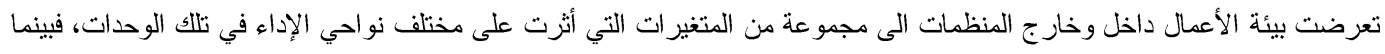

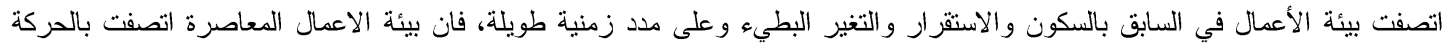

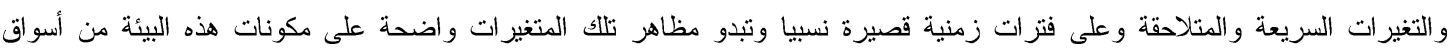

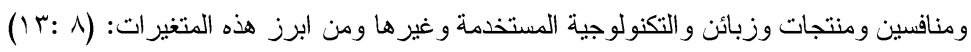

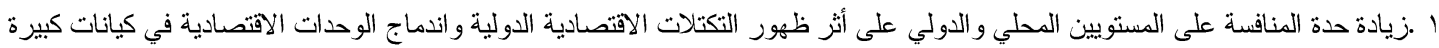

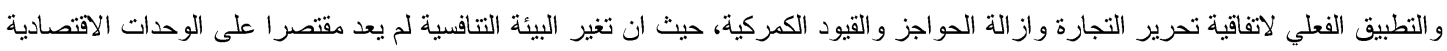

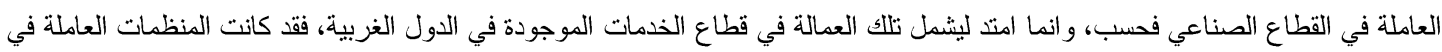
قطاع الخدمات قبل عقد الثمانينات اما احتكارات مملوكة من قبل الدولة أو مملوكة من قبل القطاع الخاص وتعمل في بيئة عالية الحماية فضلاً عن

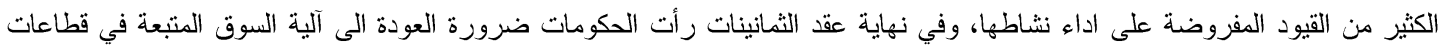

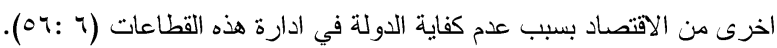

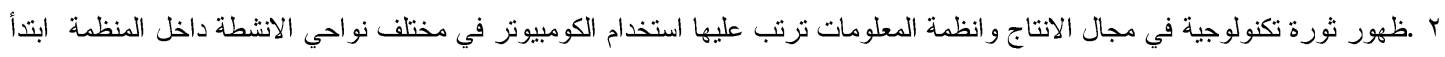

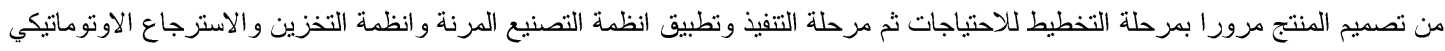
ثم مرحلة الرقابة بالاضافة الى استخدام أساليب قو اعد البيانات في تثغيل البيانات الداخلية والخارجية وامداد الادارة بالمعلومات اللازمة لاتخاذ القز ار ات بسر عة ودقة فائقة. r .ظهور تغيرات جذرية في نظام وفلسفة الادارة ومداخل اتخاذ القزار ات واساليب الانتاج ترتب عليها تطبيق الادارة الستر اتيجية وظهور فلسفة التوقيت المنضبط في المخزون ونظام الانتاج في الوقت المحدد ونظام الانتاج المرن و الجودة الثاملة وتحويل الاهتمام برقابة الجودة الى انتهاج سياسة التحسين المستمر واستخدام اسلوب التكلفة المستهدفة واسلوب تحليل سلسلة القيمة واسلوب هندسة القيمة وقد نتج عن ذلك كله مز ايا تتافسية.

\section{r-r-r-r}

ترتب على تلك المتغير ات في بيئة الاعمال المعاصرة و التي تم الاثنارة اليها انفاً، ظهور انتقادات كثيرة لنظم تقويم الاداء التقليدية التي

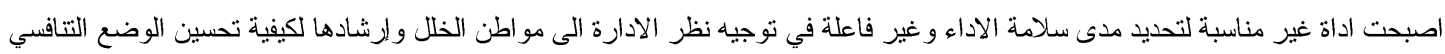

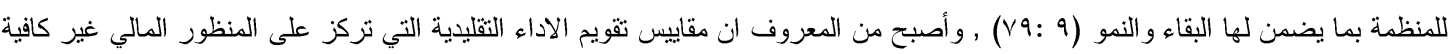

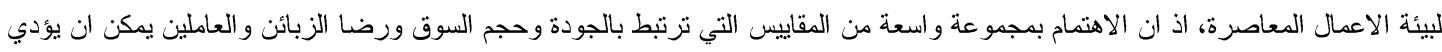
الى تبصر اكبر بالعوامل التي تسوق الاداء المالي وان القصور فيها يوفر انذارا مبكر ا بوجود قصور معين في الاداء المالي ويجعل من الممكن

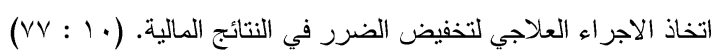

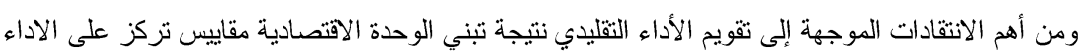

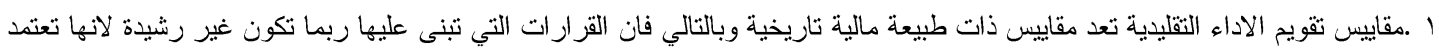

على معلومات غير ملائمة.

r بتتميز مقاييس تقويم الاداء التقليدية بالبطء الثديد في مواجهة المنظمة المنافسة تجاه الحركة السريعة و المتقلبة لاسواق المنتجات.

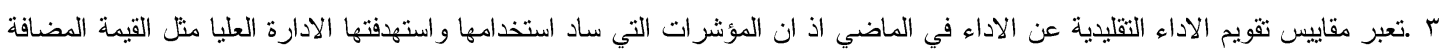
الاقتصادية وصافي الربح والعائد على الاستثمار تعكس احداث ماضية الإدية ومن ثم فهي لاترتبط كثير البالاحداث الحالية والتي يتوقع ان تؤثر في

تطوير الاداء في المستقبل.

ع .استخدام مقاييس تقويم الاداء التقليدية يؤدي الى التركيز على تحقيق النتائج في الاجل القصير على حساب تحقيق النتائج في الاجل الطويل.

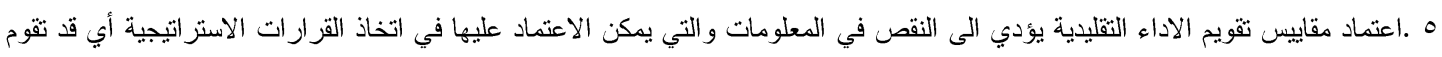

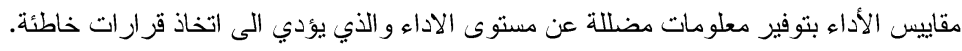

r-r ب : بطاقة الاداء المتوازن :إنموذج لتقويم الأداء المعاصر r-r-r

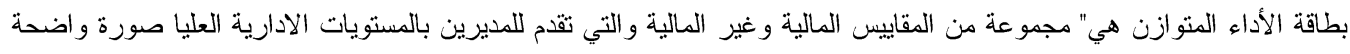
وشاملة لأداء شركاتهم (1)

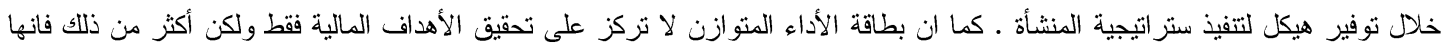

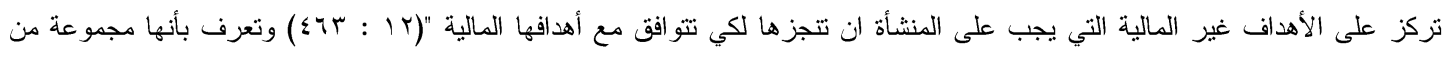

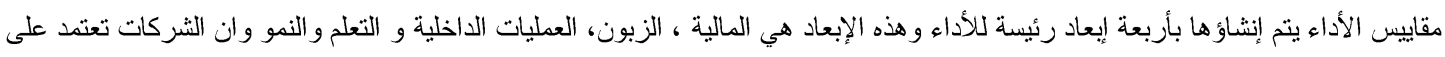


بطاقة الأداء المتو ازن التي تحتوي على مجموعة من مقاييس للأداء في كل بعد وان هذه المقاييس يمكن ربطها إستر اتيجية الثركة لتحقيق تجاهها

(r)

وتبرز أهمية بطاقة الأداء المتوازن في تقويم أداء المنظمة من خلال مايلي-:

(Yฯ9- Yчะ: 11)

1 - توضيح وتفسير وتطوير ستراتيجية المنظمة.

2-

3-توصيل الستراتيجية لجميع المستويات الإدارية في المنظمة.

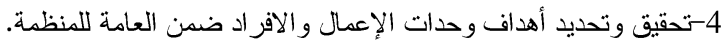

5- ربط نتائج الرقابة الدورية للأداء بالنمو و التعلم الموجه لمهارات الإفر الاد واد في المنظمة لغرض تحسين وتطوير ستر اتيجية المنظمة.

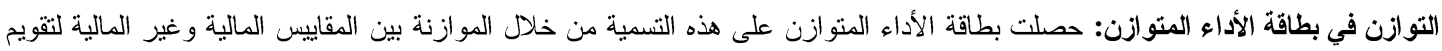

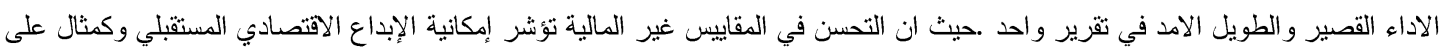

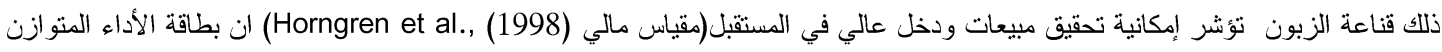

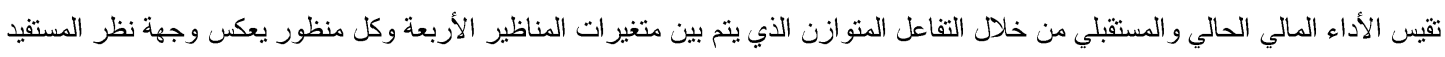

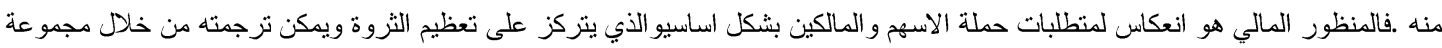

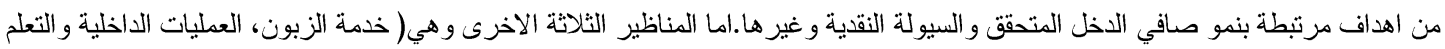

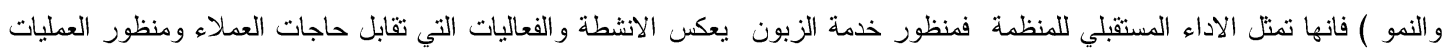

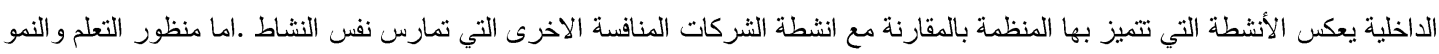
فهو يعكس عملية التفاعل بين افراد الثركة وبين الواجبات المحدده لهم ضمن الخطط الإدارية ومدى الاتساق بين اهداف الافراد و الاهداف

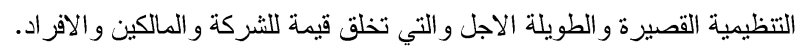

منظورات بطاقة الاداء المتوازن

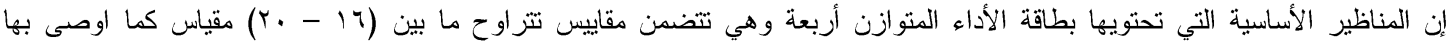
كلا) و (Kaplan \& Norton)

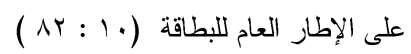

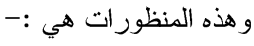
1- المنظور المالي

يعد المنظور المالي احد مناظير بطاقة الأداء المتوازن ويمثل نتاج هذا المنظور مقاييس موجهة لتحقيق الاهداف او الوقوف على مستوى

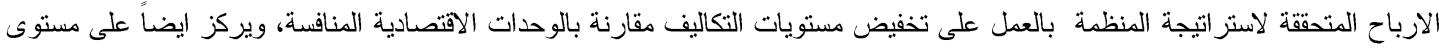
الدخل التتّغيلي و العائد على رأس المال المستثمر الناتج من تخفيض التكاليف ونمو حجم المبيعات لمنتجات حالية و العائد على حقوق المساهمين،

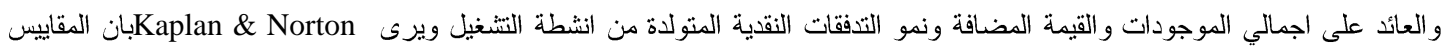
المستخدمة في تقويم الأداء المالي للوحدة الاقتصادية تختلف باختلاف المر احل التي تمر بها تلك المنظمة، حيث لخصها في ثلاث مر احل رئيسة

أ ـ مرحلة النمو :حيث تكون الوحدة الاقتصادية في المرحلة الاولى من دورة حياتها، نزكز المقاييس المالية على زيادة المبيعات والدخول في اسواق جديدة واجتذاب زبائن جدد والمحافظة على مستوى مناسب للانفاق على تطوير المنتجات وعمليات التتغيل ونتمية قدرات العاملين و امكانياتهم.

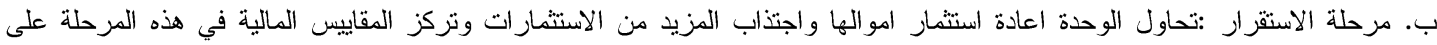
المقاييس التقليدية مثل العائد على رأس المال المستثر والدخل الدادل الناتج من التثغيل و عائد المساهمة والقيمة الاقتصادية المضافة. ج • مرحلة النضج-: فان هذه المرحلة ترغب المنظمة في حصاد نتائج الاستشمار ات في المرحلتين السابقتين وتركز المقاييس المالية على تعظيم التدفق النقدي الداخل بالاضافة الى مقاييس اخرى منل مدة الاسترداد وحجم الإير ادات.

يبين هذا المنظور مدى قدرة المنظمة على الايفاء بمنطلبات وحاجات الزبائن من السلع والخدمات وان ما تمنلك من قيمة مضافة من وجهه

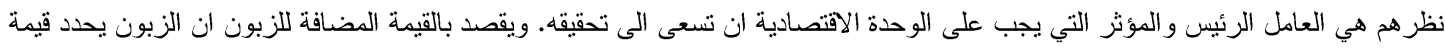

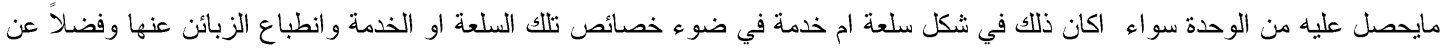

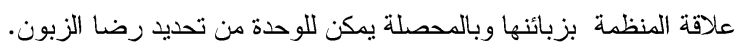


لقد اكد كل من (Kaplan \& Atkinson) أهمية هذا المنظور من منطلق إن إدارة الوحدة تسعى الى تحقيق اعلى درجة لارضاء الزبائن

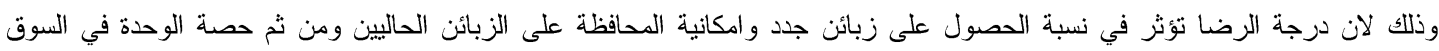

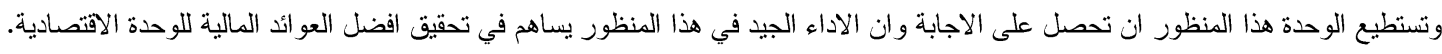

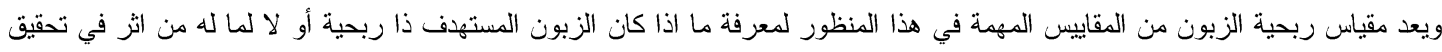

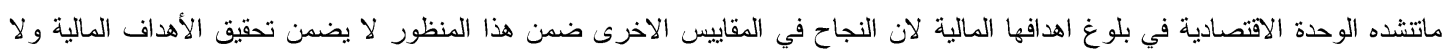

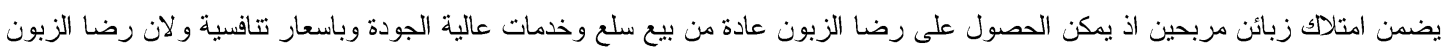

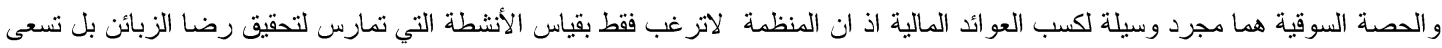

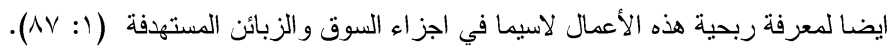

\section{r منظور العمليات الاخلية}

ويقصد بالعمليات الداخلية جميع الأنثطة والفعاليات الداخلية التي تتميز بها الوحدة عن غيرها من المنظمات و التي من خلالها يتم مقابلة

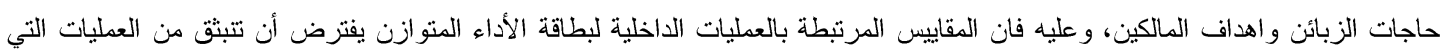

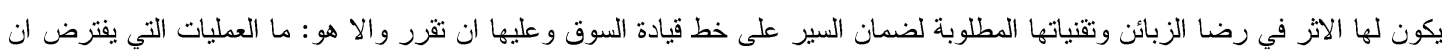

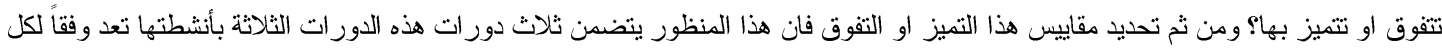

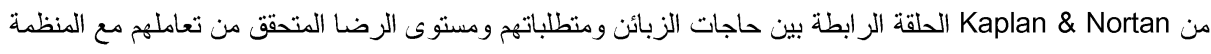

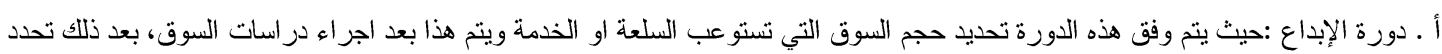
وتوضع خطة الإنتاج المطلوبة ونو عية ومعدات الإتتاج و المدة الزمنية للإنتاج. ب • دورة العمليات :تتضمن انتاج وتسليم السلع والخدمات التي تلبي احتياجات الزبون الزبون. ج · دورة الخدمات ما بعد البيع -: و التي تتزكز بها الانثطة على تحديد طييعة ونو عية الخدمات المقدمة للزبون مابعد عملية التجهيز كذلك يدخل

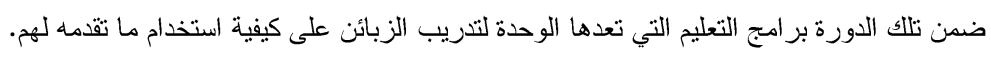

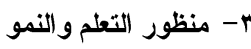

يركز هذا المنظور على تطوير قدرات العاملين داخل الوحدة الاقتصادية كونهم البنية التحتية لها والتي تعمل على بناء المنظمة وتطويرها

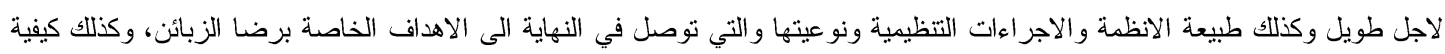

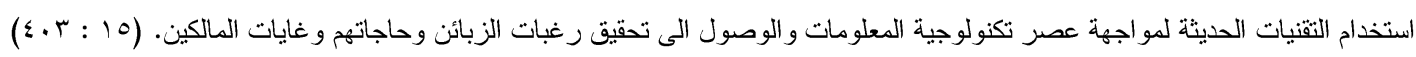

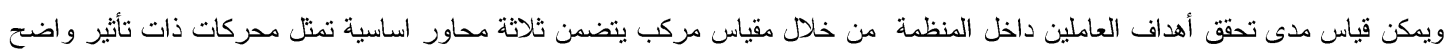

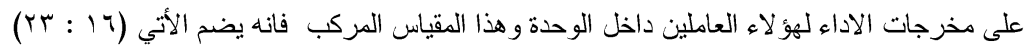

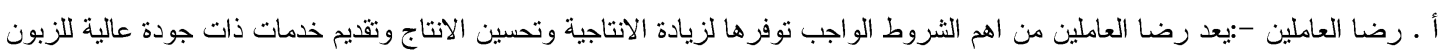

ويتم قياسها عن طريق مسوحات تتضمن:

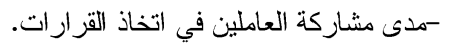
-امكانيات توصيل المعلومات الى العاملين لمساعدتهم للقيام بعملهم بشكل جيد. - الاعتر اف بانجاز العاملين عند القيام بعمل جيد. - مستوى الدعم المقدم من قبل الادارة. - درجة رضا العاملين عن الوحدة الاقتصادية.

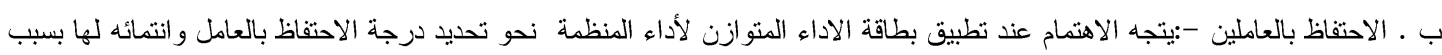

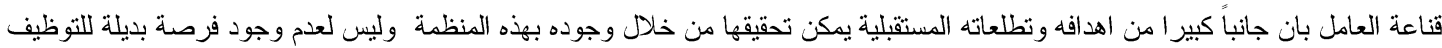

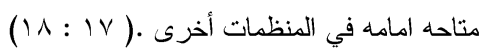
ج • انتاجية العاملين -: وتمثل المخرجات الاجمالية الناتجة عن توظيف واستخدام مهارات وقدرات العاملين في عملية التثغيل ،و الهدف في هذا

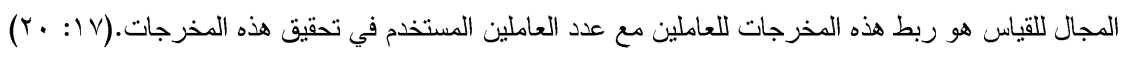

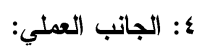

تعتمد نظرية بطاقة الأداء المتوازنة على مبدأ بناء الزبون المخلص لمنتوجات المنظمة المعنية، مقابل منحه امتيازا معينا، كأن تكون

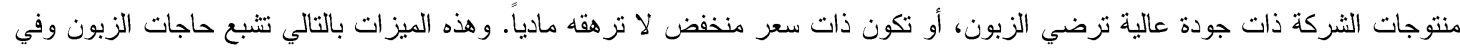

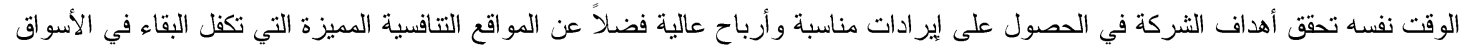




$$
\begin{aligned}
& \text { اتفق المفكرون على تضمين مقاييس بطاقة الأداء المنوازنة في أربعة أركان: }
\end{aligned}
$$

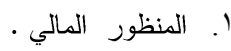

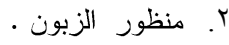

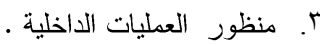

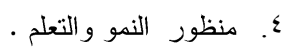

وسيتم فيما يلي عرض مفاهيمها وأهداف ومقاييس كل منها بالتفصيل لتسهيل عملية تطبيق مقاييس بطاقة الأداء المتوازنة على الثركة. ا 1 - المنظور المالي

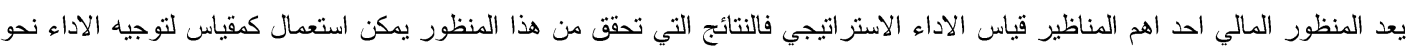

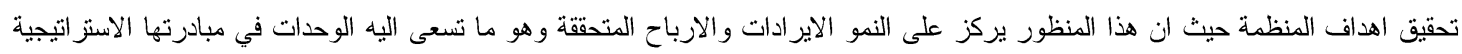

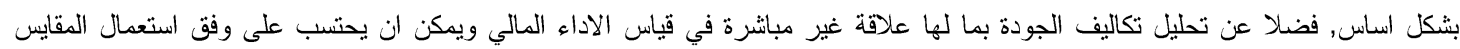
الاتية:

$$
\text { أ أ - العائد على الاستثمار }
$$

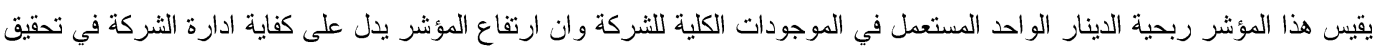

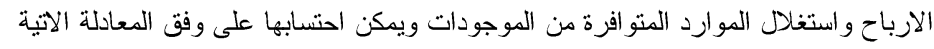

$$
\begin{aligned}
& \text { صافي الربح بعد الضريبة }
\end{aligned}
$$

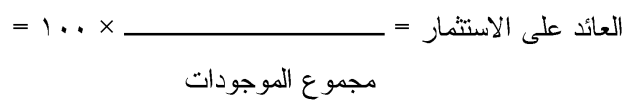

rVSOTVITTYTY

$\% 19, r q=1 \ldots \times$

ISIT. rqATIVIT

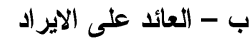

وتعطي هذه النسبة مؤشر الربحية ومدى كفاءة ادارة المشروع وفريق العمل في تخفيض التكاليف وتحسب هذه النسبة من خلال المعادلة الاتية :

$$
\begin{aligned}
& \text { صافي الربح بعد الضريبة }
\end{aligned}
$$

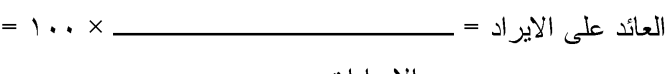

$$
\begin{aligned}
& \text { الايز ادات }
\end{aligned}
$$

rVEOTYITYYTY

$$
\begin{aligned}
& \text { العائد على الاير اد = }
\end{aligned}
$$

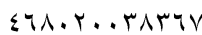

$$
\begin{aligned}
& \text { ج - نمو اير اد المبيعات } \\
& \text { اير اد المبيعات الحاليه - اير اد المبيعات السابقة }
\end{aligned}
$$

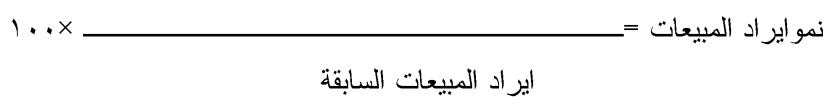

$$
\begin{aligned}
& \text { EOVOVEVY. I. T - EMA. Y..rATTV }
\end{aligned}
$$



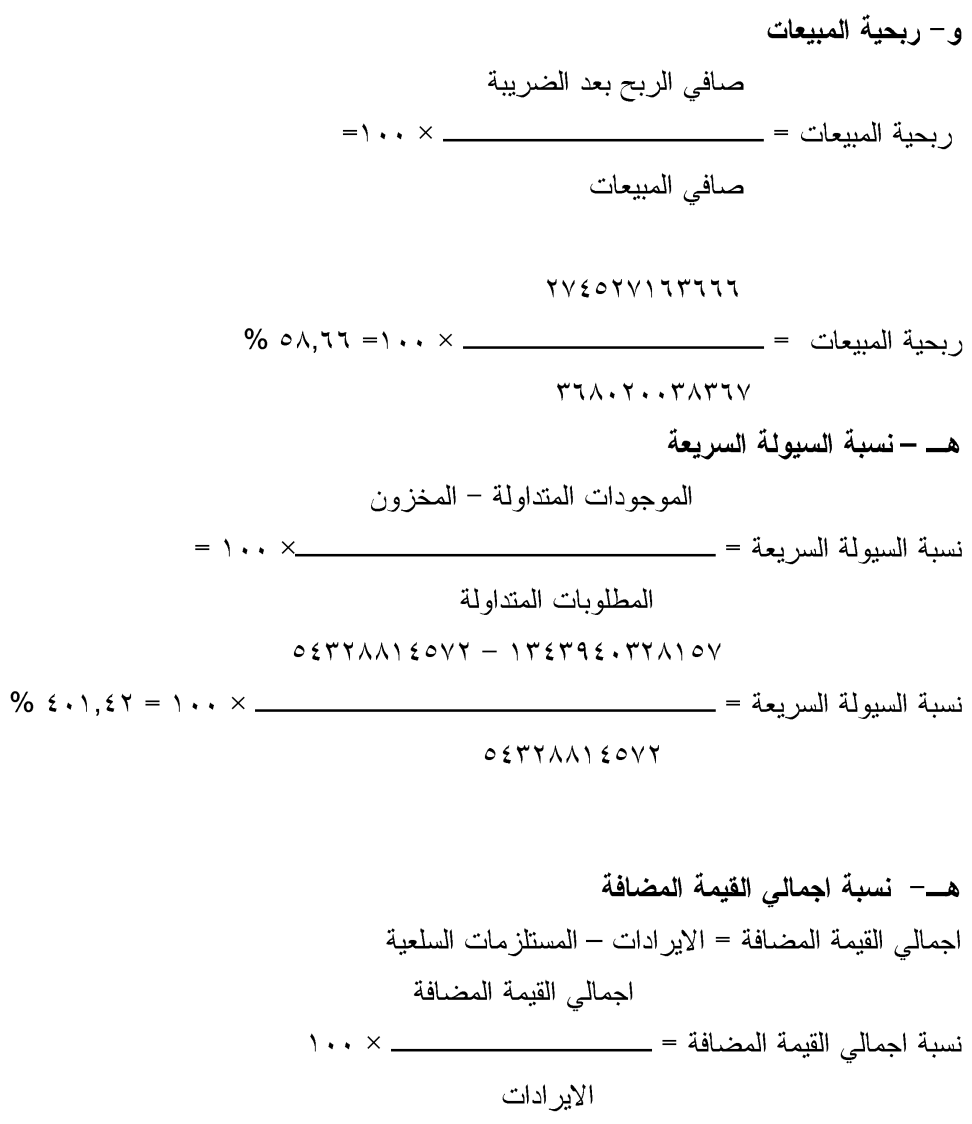

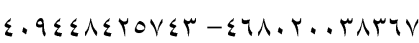

$\% 1 r, 01=1 \ldots x$ نسبة اجمالي القيمة المضافة $\varepsilon \cdot 9 \leqslant \leq \Lambda \leq r \circ V \leqslant r$

ز - نسبة تكاليف الرقابة الى تكاليف الجودة وتمثل هذه النسبة مقدار المبالغ المستثمرة في انتطة الوقاية والتقيم , اذ كلما زاد الاستثمار في هذين العنصرين تتخفض تكاليف الفشل وتحسب هذه النسبة في المعادلة الاتية

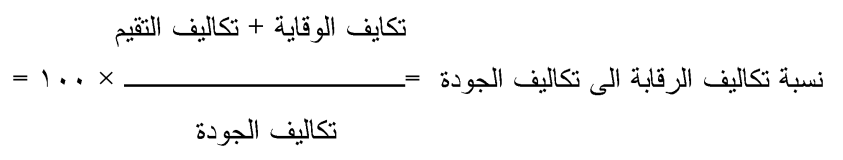

$1 \leqslant 1 V T r \leqslant r V q+0 \leqslant 01 r \leqslant 170 r$ $\% \wedge 1$, or $=1 \ldots \times$

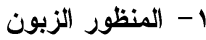

يهتم الزبون بعدة امور ابرزها الوقت والجودة والاداء و الكلفة وسيتم استعمال المقايس الاتية

أ- الحصة السوقية

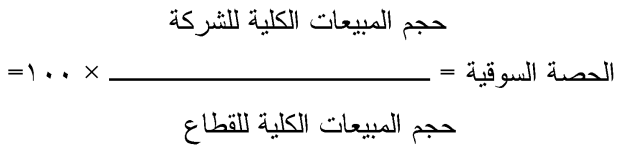




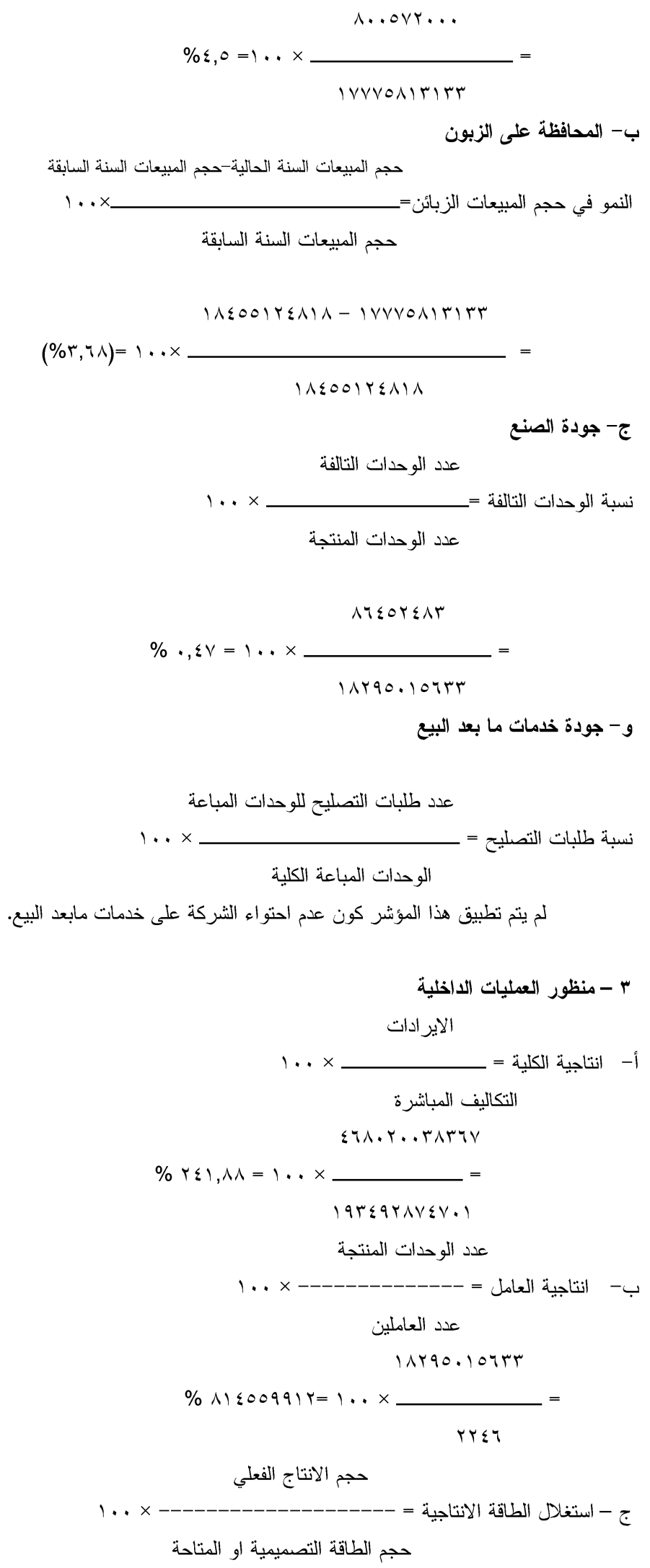




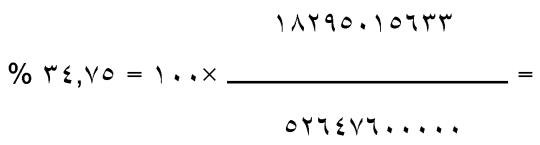

ه - م-كاليف فحص جودة مر احل الاتتاج

م .السيطرة النوعية للسنة الحالية - م السيطرة النوعية للسنة السابقة

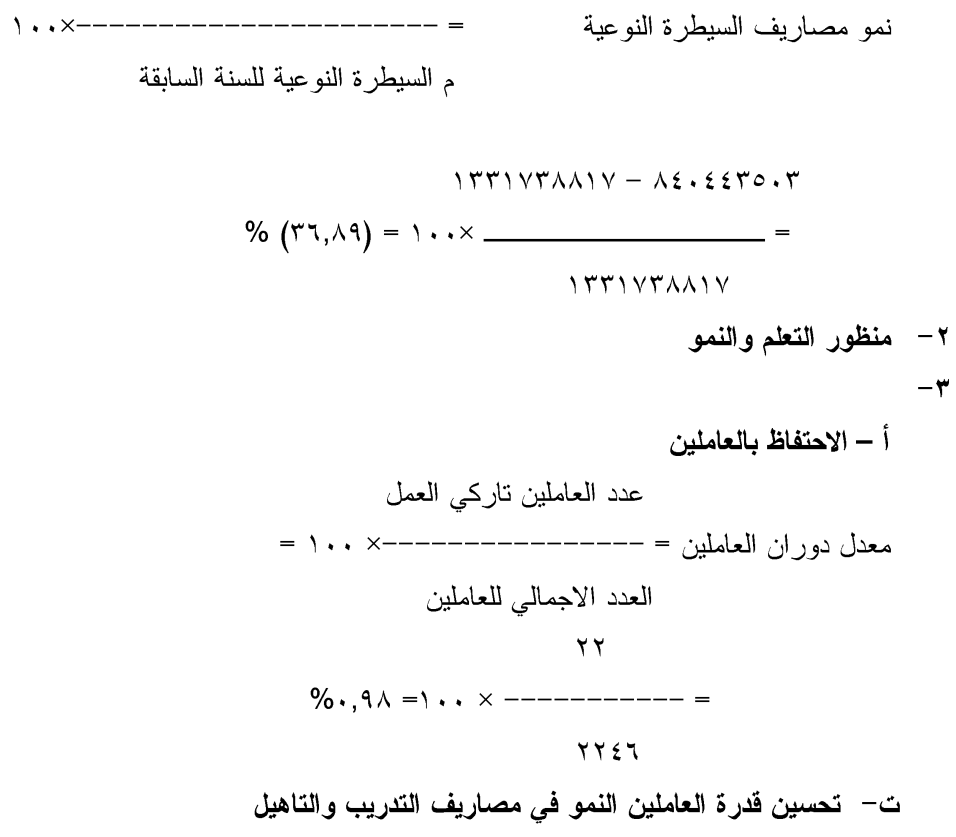




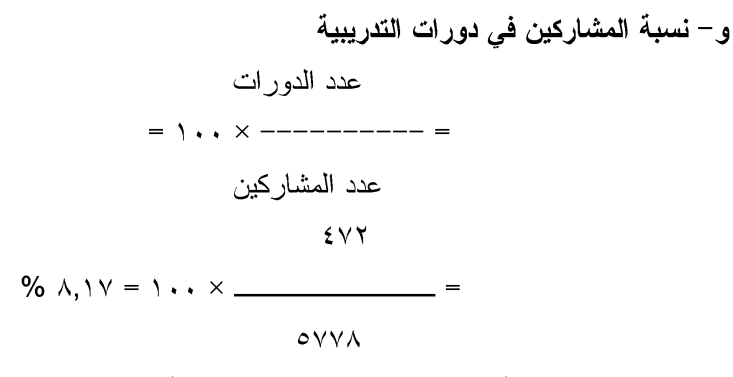

المبالغ المنفقة على خدمة العاملين للسنة الحالية - المبالغ المنفقة على خدمة العاملين للسنة السابقة

المبالغ المنفقة على خدمة العاملين للسنة السابقة

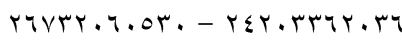

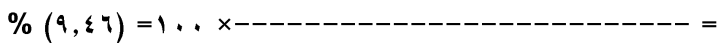

TYVTY.T.OT.

تحديد درجات تقويم الاداء للمديرية العامة لاتتاج الطاقة الكهربائية/ الفرات الاوسط جدول رقم (1)

\begin{tabular}{|c|c|c|c|c|c|}
\hline الارجة المتحققة & المؤشر المتحقق & النسبة المعتمدة في & الوزن النسبي & المقياس & المنظور \\
\hline \multirow[t]{7}{*}{ v } & $\% 19.49$ & اكثر من r| & $v$ & \multirow[t]{7}{*}{ العائد على الاستثمار } & المالي \\
\hline & & $1 r-1$ & 1 & & \\
\hline & & $1 \cdot-1$ & 0 & & \\
\hline & & $\lambda-4$ & $\varepsilon$ & & \\
\hline & & $\Lambda-\varepsilon$ & $r$ & & \\
\hline & & $\varepsilon-r$ & $r$ & & \\
\hline & & اقل من r & 1 & & \\
\hline \multirow[t]{13}{*}{9} & $\% 01.74$ & اكثر 10 & 9 & \multirow[t]{9}{*}{ العائد على الايرادات } & \\
\hline & & $10-14$ & $\wedge$ & & \\
\hline & & $|r-1|$ & 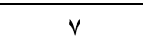 & & \\
\hline & & $11-9$ & 4 & & \\
\hline & & $9-v$ & 0 & & \\
\hline & & $v-0$ & $\varepsilon$ & & \\
\hline & & $0-r$ & $r$ & & \\
\hline & & $r-1$ & $r$ & & \\
\hline & & اقل من 1 & 1 & & \\
\hline & & (كثر من . & 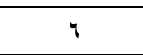 & \multirow[t]{6}{*}{ نمو ايرادات المبيعات } & \\
\hline & & $0 .-\{0$ & 0 & & \\
\hline & & $\varepsilon 0-\varepsilon$. & $\varepsilon$ & & \\
\hline & & $\varepsilon \cdot-\mu$. & $r$ & & \\
\hline \multirow[t]{2}{*}{ r } & \%rr.Ar & $r .-1$. & r & & \\
\hline & & (قل من · 1 & 1 & & \\
\hline \multirow[t]{4}{*}{$\varepsilon$} & $r \bullet, \cdot \Lambda$ & اكثر من 10 & $\varepsilon$ & \multirow{4}{*}{ العائد على حقوق } & \\
\hline & & $10-1$. & $r$ & & \\
\hline & & $1 .-0$ & $r$ & & \\
\hline & & اقل من • & 1 & & \\
\hline \multirow[t]{4}{*}{$\varepsilon$} & $\% \circ 1.74$ & اكثر من 10 & $\varepsilon$ & \multirow[t]{4}{*}{ ربحية المبيعات } & \\
\hline & & $10-1$ & $r$ & & \\
\hline & & $1 \cdot-0$ & r & & \\
\hline & & اقل من ه & 1 & & \\
\hline
\end{tabular}




\begin{tabular}{|c|c|c|c|c|c|}
\hline الارجة المتحققة & المؤشر المتحقق & النسبة المعنمدة في & المون النسبي & المقياس & المنظور \\
\hline \multirow[t]{13}{*}{$\wedge$} & $\% \varepsilon .1 . \varepsilon r$ & اكثر من . 1. & $\wedge$ & \multirow{8}{*}{ نسبة السيولة } & المالي \\
\hline & & $1 \ldots-\Lambda$ & $\mathrm{v}$ & & \\
\hline & & 1.-4. & 7 & & \\
\hline & & $7 .-0$. & - & & \\
\hline & & $0 .-\varepsilon$. & $\varepsilon$ & & \\
\hline & & $\varepsilon \cdot-r$. & $r$ & & \\
\hline & & $r .-r$. & r & & \\
\hline & & اقل من · r & 1 & & \\
\hline & & اكثر من . & $\wedge$ & \multirow{8}{*}{ المضالي القيمة } & \\
\hline & & $7 .-0$. & v & & \\
\hline & & $0 .-\varepsilon$. & 7 & & \\
\hline & & $\varepsilon \cdot-\mu$. & . & & \\
\hline & & r.-r. & $\varepsilon$ & & \\
\hline \multirow[t]{3}{*}{$r$} & $\mid r .01$ & r. -1 . & $r$ & & \\
\hline & & $1 .-0$ & r & & \\
\hline & & & 1 & & \\
\hline \multirow[t]{4}{*}{$v$} & 11.0r & V. اكثر من V & $v$ & \multirow{6}{*}{ نسبة تكاليف الرقابة } & \\
\hline & & $7 .-0$. & 7 & & \\
\hline & & $0 .-\varepsilon$. & . & & \\
\hline & & \&. - . & $\varepsilon$ & & \\
\hline \multirow[t]{3}{*}{$r$} & \%rr.Ar & r.-r. & $r$ & & \\
\hline & & $r \cdot-1$. & $r$ & & \\
\hline & & اقل من · 1 & 1 & & \\
\hline$\varepsilon \varepsilon$ & & & 00 & \multicolumn{2}{|c|}{ المجموع المنظور المالي } \\
\hline
\end{tabular}

جدول رقم (Y)

\begin{tabular}{|c|c|c|c|c|c|}
\hline الارجة المتحققة & المؤشر المتحقق & النسبة لمعتمدة في & الوزن النسبي & المقياس & المنظور \\
\hline & & 9. اكثر من & 1. & \multirow{10}{*}{ الحصة العوفية } & \multirow{12}{*}{ منظور الزبون } \\
\hline & & $9 .-\Lambda$ & 9 & & \\
\hline & & $\Lambda .-v$. & $\wedge$ & & \\
\hline & & V. - . & $v$ & & \\
\hline & & $1 .-0$. & 7 & & \\
\hline & & $0 .-\varepsilon$. & 0 & & \\
\hline & & $\varepsilon .-r$. & $\varepsilon$ & & \\
\hline & & $r .-r$. & $r$ & & \\
\hline & & Y. -1 . & $r$ & & \\
\hline \multirow[t]{3}{*}{1} & $\%\{, 0$ & اقل من · & 1 & & \\
\hline & & 9. اكثر من 9 & 1. & \multirow{2}{*}{ المحافظة على } & \\
\hline & & $9 .-\Lambda$. & 9 & & \\
\hline
\end{tabular}




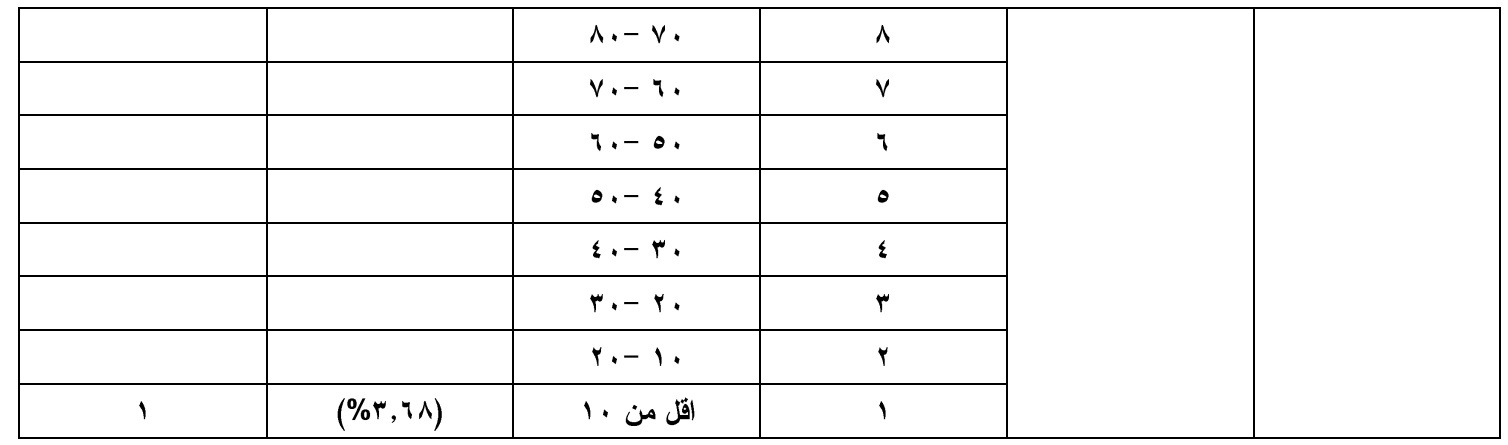

\begin{tabular}{|c|c|c|c|c|c|}
\hline & & اكثر من • & 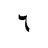 & \multirow{6}{*}{ جودة الصنع } & \multirow{9}{*}{ منظور الزبون } \\
\hline & & $1 .-1$ & 0 & & \\
\hline & & $\Lambda-1$ & $\varepsilon$ & & \\
\hline & & $7-\varepsilon$ & r & & \\
\hline & & $\varepsilon-r$ & r & & \\
\hline \multirow[t]{5}{*}{1} & $\% . . \leqslant 9$ & اقل من r & 1 & & \\
\hline & & اكثر من 0 & r & \multirow{3}{*}{ جودة خدمات ما بعد } & \\
\hline & & $0-r$ & r & & \\
\hline & & اقل من r & 1 & & \\
\hline & & & 19 & \multicolumn{2}{|c|}{ مجموع منظور الزبون } \\
\hline
\end{tabular}

جدول رقم (r)

\begin{tabular}{|c|c|c|c|c|c|}
\hline الارجة المتحقة & المؤشر المتحقق & النسبة لمعتمدة في & الوزن النسبي & 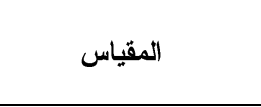 & 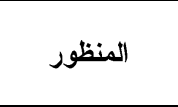 \\
\hline$r$ & $\Lambda 1 \leq 00991 r$ & اكثر من . 1. & $r$ & \multirow{3}{*}{ انتاجية العامل } & \multirow{12}{*}{ منظور العمليات } \\
\hline & & $1 \ldots-0$ & $r$ & & \\
\hline & & اقل من • & 1 & & \\
\hline$r$ & $\% \quad r \leqslant 1, \wedge \wedge$ & اكثر من . 1. & $r$ & \multirow{3}{*}{ الاتتاجية الكلية } & \\
\hline & & $1 \ldots-0$ & r & & \\
\hline & & اقل من •• & 1 & & \\
\hline$r$ & $\% r \varepsilon, v \bullet$ & r. اكثر من r r & $r$ & \multirow{3}{*}{ استغلال الطاقة } & \\
\hline & & $r \cdot-1$. & $r$ & & \\
\hline & & اقل من 1 & 1 & & \\
\hline & & r. اكثر من r r & $r$ & \multirow{3}{*}{ تكاليف الفحص جودة } & \\
\hline & & $r \cdot-1$. & $r$ & & \\
\hline 1 & $\%\left(\sim_{4}, \wedge 9\right)$ & اقل من • & 1 & & \\
\hline 1. & & & ir & \multicolumn{2}{|c|}{ مجموع منظور العمليات الداخلية } \\
\hline
\end{tabular}




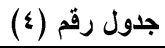

\begin{tabular}{|c|c|c|c|c|c|}
\hline اللارجة المتحققة & المؤشر المتحقق & النسبة لمعتدة في & الوزن النسبي & المقياس & 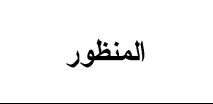 \\
\hline & & اكثر من r | اكن & r & \multirow{2}{*}{ الاحتفاظ بالعاملين } & \multirow{14}{*}{ منظور التعلم والنمو } \\
\hline 1 & $\% \cdot, 9 \wedge$ & اقل من r - ما & 1 & & \\
\hline & & اكثر من r & r & تحسين قدرة & \\
\hline 1 & $\%(r Y .\{\wedge)$ & اقل من r & 1 & العاملين & \\
\hline & & اكثر من • إم & r & \multirow{2}{*}{ الابتكار والابداع } & \\
\hline & & اقل من • & 1 & & \\
\hline & & اكثر من · 1 & r & \multirow{2}{*}{ نسبة المشاركين في } & \\
\hline \multirow[t]{3}{*}{1} & $\% \wedge, I \vee$ & اقل من 1 & 1 & & \\
\hline & & اكثر من . 1. & $r$ & \multirow{3}{*}{ المكافئات التشجيعية } & \\
\hline & & $1 \cdots-0$. & r & & \\
\hline \multirow[t]{3}{*}{1} & $\%\left(v_{0}\right)$ & اقل من • • & 1 & & \\
\hline & & اكثر من - 1 & $r$ & \multirow{3}{*}{ و نمو المبالغ المنفقة } & \\
\hline & & $1 .-0$ & r & & \\
\hline \multirow[t]{2}{*}{1} & $\%(9, \leqslant 4)$ & اقل من • & 1 & & \\
\hline & & & $1 \varepsilon$ & \multicolumn{2}{|c|}{ مجموع منظور التعلم والنمو } \\
\hline
\end{tabular}

جدول رقم (•) - (•) - (ب)

\begin{tabular}{|c|c|c|c|}
\hline & & & 1- - المنظور المالي \\
\hline الدرجة & المؤشر & المقاييس & الاهداف \\
\hline$v$ & $\% 19, r q$ & العائد على الاستثمار & الربحية \\
\hline 9 & $\% \bullet \wedge, 14$ & العائد على الاير اد & \\
\hline$r$ & $\%$ Yr,AT & نمو المبيعات & \\
\hline$\varepsilon$ & $\%$ ro,.A & العائد على حقوق الملكية & \\
\hline$\varepsilon$ & $\% \bullet \wedge, 14$ & ربحية المبيعات & \\
\hline$\wedge$ & $\% \varepsilon, 1, \varepsilon r$ & نسبة السيولة & \\
\hline$r$ & $\%(r, 0)$ & اجمالي القيمة المضافة & \\
\hline$v$ & $\% \wedge 1$, ० & نسبة تكاليف الرقابة الى تكاليف & تخفيض التكاليف \\
\hline$\varepsilon \varepsilon$ & & 00 & المجموع \\
\hline
\end{tabular}

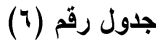

\begin{tabular}{|c|c|c|c|}
\hline & & & المنظور الزبائن \\
\hline الدرجة & المؤشر & المقاييس & الاهداف \\
\hline 1 & $\%(r, \uparrow \wedge)$ & محافظة على الزبون & \multirow{2}{*}{ رضا الزبون } \\
\hline \multirow[t]{2}{*}{1} & $\% \cdot, \leqslant 9$ & جودة الصنع & \\
\hline & & جودة خذمات ما بعد البيع & تحسين جودة الثركة \\
\hline$r$ & & 19 & المجموع \\
\hline
\end{tabular}




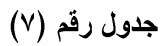

\begin{tabular}{|c|c|c|c|}
\hline & & & r - المنظور العمليات الداخلية \\
\hline الارجة & 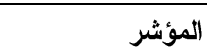 & المقاييس & الاهداف \\
\hline$r$ & $\% r\{1, \wedge \wedge$ & الاتتاجية الكلية & \multirow[t]{3}{*}{ ت تحسين الاتتاجية } \\
\hline$r$ & $\% \wedge l\{\Delta \Delta ৭ q 1$ r & انتاجية العامل & \\
\hline$r$ & $\% r \varepsilon, v \circ$ & استغلال الطاقة & \\
\hline 1 & $(\% 4 . \wedge 9)$ & تكاليف الفحص جودة مراحل الاتتاج & تحسين جودة العمليات \\
\hline 1. & & ir & 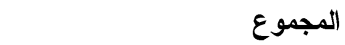 \\
\hline
\end{tabular}

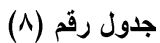

\begin{tabular}{|c|c|c|c|}
\hline & & & ع - منظور التعلم والنم \\
\hline 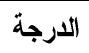 & المؤشر & المقاييس & الاهداف \\
\hline 1 & $\% \cdot, 9 \wedge$ & الاحتفاظ بالعاملين & \multirow[t]{6}{*}{ تحسين قدرة العاملين } \\
\hline 1 & $\%($ YY, Y^) & تحسين قدرة العاملين & \\
\hline - & 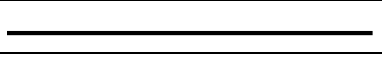 & الابتكار و الابداع & \\
\hline 1 & $\% \wedge, \perp \vee$ & نسبة المشاركين في دورات التثريبية & \\
\hline 1 & $\%(\mathrm{v} \bullet)$ & المكافئات التثجيعية و الحو افز & \\
\hline 1 & $\%(9, \varepsilon \uparrow)$ & والخدمات الممنوحة للعاملين المنفل & \\
\hline - & & $1 \varepsilon$ & المجموع \\
\hline
\end{tabular}

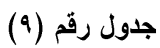

\begin{tabular}{|c|c|c|c|}
\hline 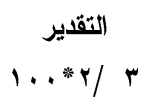 & الارجة التي حصلت عليها الثركة & الارجة الكلية & المنظور \\
\hline$\% \wedge$. & $\varepsilon$ & 00 & المالي \\
\hline$\% 1$. & r & 19 & الزبون \\
\hline$\% \wedge r$ & 1. & ir & العمليات الداخلية \\
\hline \%ro & 。 & $1 \varepsilon$ & التعلم و النمو \\
\hline$\% \uparrow 1$ & 11 & $1 \ldots$ & المجموع \\
\hline
\end{tabular}

ه- - الاستتناجات و التوصيات:

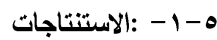

ه-1-1 - 1- الاستتتاجات المتعلقة بالجانب النظري

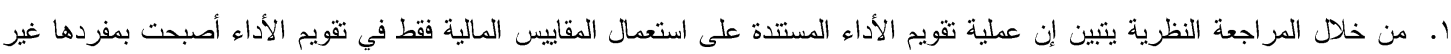

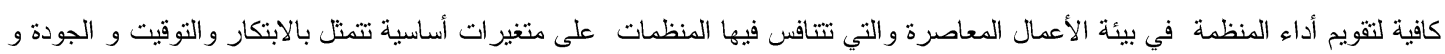

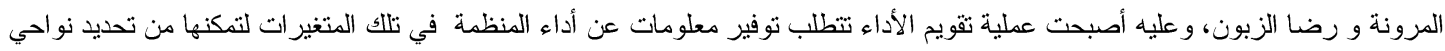

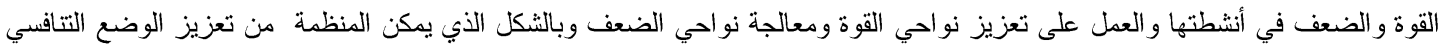

r. قد ظهرت الحاجة إلى استعمال مجموعة متر ابطة من الدقاييس المالية وغير المالية في عملية تقويم أداء المنظمة ينسجم مع متغيرات بيئة

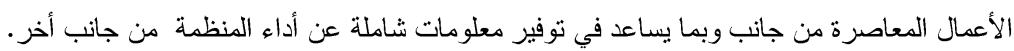

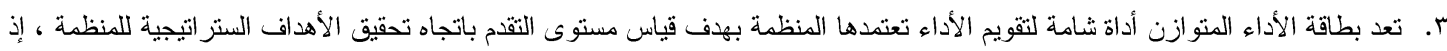

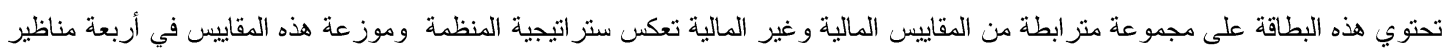

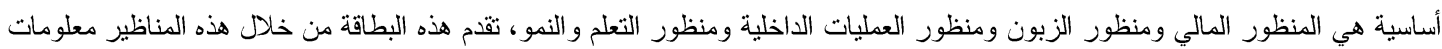
شاملة عن أداء الوحدة الاقتصادية. ع. من خلال بطاقة الاداء المتوازن يمكن تحقيق اهداف استراتيجية بواسطة العناصر الاربعة المترابطة من زيادة نسبة النمو في العوائد وتخفيض الكلف للوحدات الاقتصادية. 
ه. لغرض تطبيق بطاقة الأداء المتوازن بنجاح في الوحدات الاقتصادية يتطلب توافر مجموعة من المتطلبات من أهمها ان تكون الأهداف الستر اتيجية للمنظمة قابلة للقياس الكمي باستعمال مقاييس ملائمة فضلا عن وجود الدافعية لدى المنظمة لاختيار وتطبيق بطاقة الأداء المتوازن.

\section{ه-1- - - الاستتتاجات المنعلقة بالجانب العملي}

ا- هنالك نجاح عام لاى المنظمة عينة البحث في تطبيق بطاقة الأداء المتوازن حيث حصلت محاور بطاقة الأداء المتوازن مجتمعة على تقدير

r- اظهز محور الزبائن ضعفا كبيرا لدى المنظمة عينة البحث حيث حصل على (•1\%) فقط مما يدل على ضعف واضح لاى المنظمة عينة البحث في تلبية متطلبات الزبائن وتحقيق رضاهم.

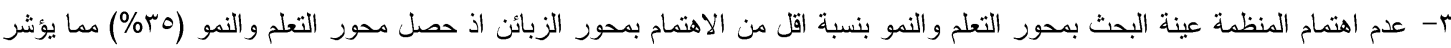

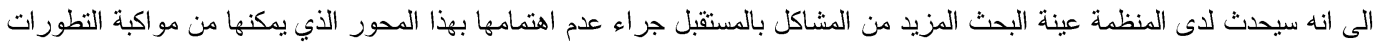

1- العمل على البناء السليم لأسس تقويم الأداء وذلك اعتماد المنظمة على مجموعة متكاملة ومتر ابطة من مقاييس الأداء المالية وغير المالية

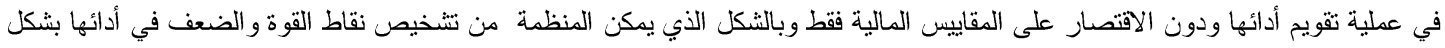
و اضح وشامل.

r- حث المنظمات على تطبيق بطاقة الأداء المتو ازن كونها أداة لتقويم الأداء الثشامل ولمختلف أجز اء الوحدة الاقتصادية.

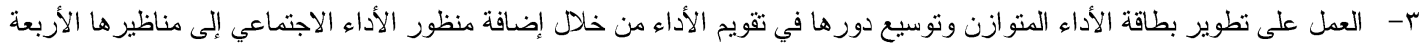

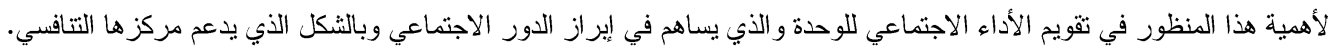

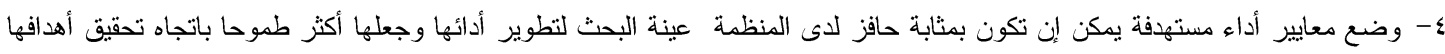

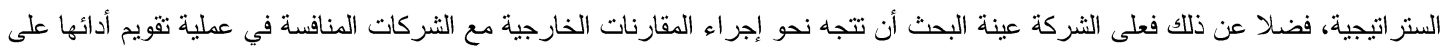
إجر اء المقارنات الاخلية. على المنظمة المبحوثة الاهتمام أكثر بمدحوري الزبائن والتعلم والنمو لتلبية توقعات زبائنها ومواكبة التطور الحاصل في البيئة الخارجية

\section{CONFLICT OF INTERESTS}

ونقلع الى البيئة الداخلية.

There are no conflicts of interest.

$$
\begin{aligned}
& \text { ا- المصادر النعيمي، نادية شاكر، التكامل بين تقنيتي بطاقة الأداء المتوازن والمقارنة المرجعية لأغراض تقويم الأداء الستراتيجي في الوحدات }
\end{aligned}
$$

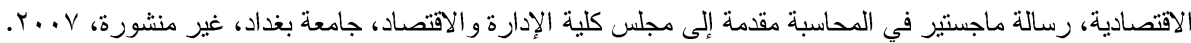

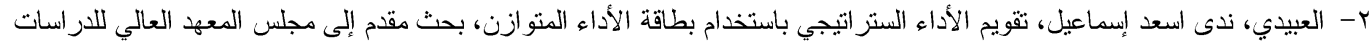

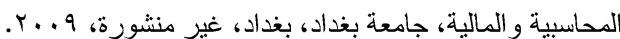

3- Blocher, Edward J., Stout, David E., Cokins, Gaey, Cost Management: A strategic Emphasis, 5th ed.,( McGraw-Hill Co., 2010).

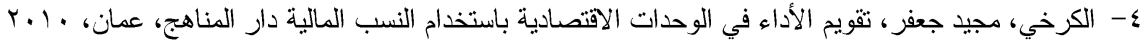

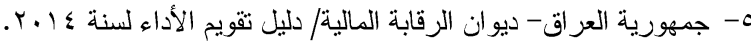

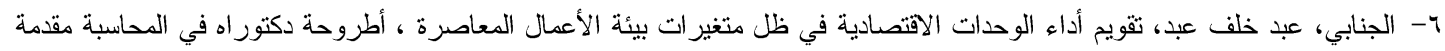

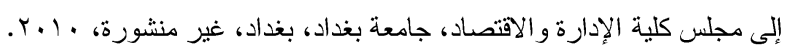

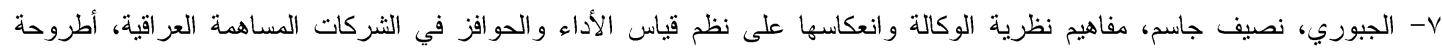

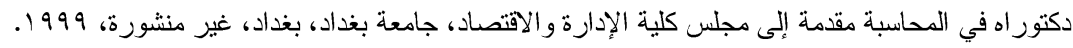

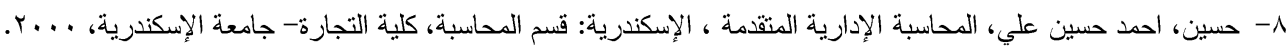

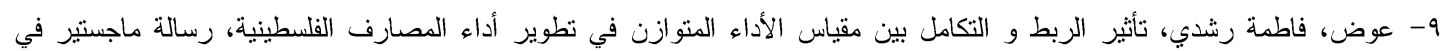

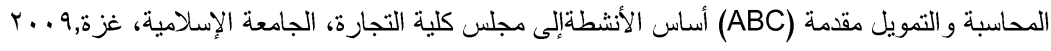

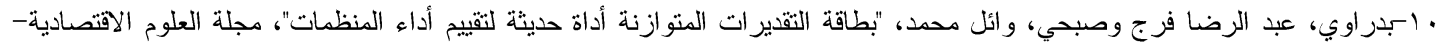

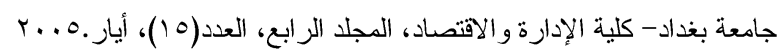

11- Kaplan, Robert S., Norton, David P., “The Balanced Scorecard Measures that drive Performance”, Harvard Business Review, January-February, 2000.

12- Horngren, Charles, Foster, Datar George and srikant, Datar "Cost Accounting A managerial emphasis" 10th ed, prentice -Hall 2000. 
13- Jiambalvo, James Management Accounting , John Wiley an sons Inc us, A 2001.

$$
\begin{aligned}
& \text { ع ا-أبو قمر، محمد احمد محمد، تقويم أداء بنك فلسطين المحدود باستخدام بطاقة الأداء المتوازن، رسالة ماجستير في المحاسبة والتمويل مقدمة }
\end{aligned}
$$

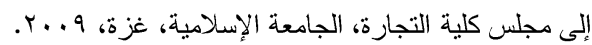

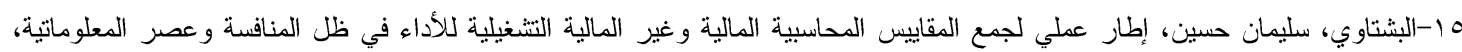

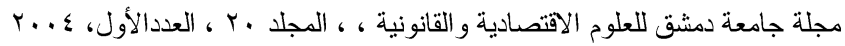

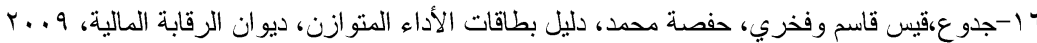

17-Kaplan, Robert S., Atkinson, Antony. A., Advanced Management Accounting, 3rd ed., (New Jersey, PrenticeHall, Inc., 1998Horngren, Charles, Foster, Datar George and srikant, Datar "Cost Accounting A managerial emphasis" 10th ed, prentice -Hall 2002. 